\title{
How CEO Deans in Academic Pharmacy Describe and Manage High-performing and Low-performing Faculty
}

\author{
Shane P. Desselle, RPh, PhD, FAPhA'; David P. Zgarrick, PhD, FAPhA ${ }^{2}$ \\ ${ }^{1}$ Touro University California College of Pharmacy; ${ }^{2}$ Northeastern University, Bouve College of Health Sciences School of Pharmacy
}

\begin{abstract}
Objectives: Gather Chief Executive Officer (CEO) deans' perspectives on: distinguishing a "star" faculty versus one that is "productive"; faculty who are "deadweight" to the organization; the role of organizational fit in defining stars and deadweight faculty; current efforts to recruit and retain star faculty; and the actions taken in regard to deadweight faculty.

Methods: A focus group panel of CEO deans was convened at the American Association of Colleges of Pharmacy (AACP) 2019 Interim Meeting. A semi-structured interview based on an organizational behavior framework was used to guide discussion in the focus group. Content analysis with axial coding was used to uncover themes from the data.

Results: Panelists indicated productivity to be a given, but that star faculty are the ones who exhibit extraordinary citizenship and leverage their talents and networks to make the program and their peers more effective. They identified nascent activities with the need to strengthen those in regard to recognizing star faculty. The panelists explicitly distinguished between deadweight, or unproductive faculty versus those who are more deleterious, even while the former might actually present a more challenging human resources management situation.

Conclusions: The research corroborated the growing recognition of the importance of faculty comportment with behaviors that extend beyond performance metrics, alone. The findings can serve as a platform for additional studies that guide decision making for organizational effectiveness in academic pharmacy.
\end{abstract}

Keywords: faculty performance, star employees, faculty retention, faculty development, organizational citizenship

\section{INTRODUCTION}

Organizational culture literature is replete with descriptions of high- and low-performing employees. While descriptions of such evolve over time, there is still much terminology used and studies employing "star" and "deadweight" employees. In fact, the research on "star" employees continues to grow. Star employees are said to be those with disproportionately high and prolonged performance, visibility, and relevant social capital, with the latter comprised of social networks that promote trust, satisfaction level, and quality of communication in an organization. ${ }^{1}$ Call et al. segmented the research on star employees, suggesting that there is assumed to be strong and ubiquitous positive effects exerted by stars on company performance. ${ }^{2}$ Downs suggests that star employees produce much of an organization's beneficial outputs, serving to offset the impact of relatively unproductive employees. ${ }^{3}$ In a series of experiments, Kim found that the loss of star employees exerted a multiplicative detriment on organizational performance. ${ }^{4}$

Reigle observed that star employees provide good examples of the aptitude, attitude, motivation, and fit that most organizations desire. ${ }^{5}$ Reisz concurred that an organization's success is determined by the people who work there and that success has often been borne from the achievements of its star

Corresponding author: Shane P. Desselle, RPh, PhD

Touro University California College of Pharmacy

Email: shane.desselle@tu.edu; Phone: 918-892-1168 employees, through things such as innovative ideas and unique approaches to achieve their organization's goals. ${ }^{6}$ The impact of star employees has ramifications for science and academia. Zucker and Darby found that star bioscientists had profound effects on the pecuniary value of an organization even well after their departure. ${ }^{7}$ They found that these stars at first tend to collaborate within their own institution before extending their collaborative networks outside of it. In fact, more recent research has demonstrated that star scientists attract one another, and they tend to migrate to organizations with other star scientists to bolster their own chances of success and be affiliated with highly reputable colleagues and organizations, not much differently than star athletes tend to migrate toward certain organizations that will enhance their earnings potential and the likelihood of playing for a championship. ${ }^{8}$

Faculty stars have demonstrated consistent entrepreneurship for their institutions, not only in discovering new knowledge and generating grants, publications and patents, but also engaging their respective industry and professional organizations for collaboration and developing innovative partnerships with the local community. ${ }^{9}$ Star faculty are attracted not only to academic institutions with other stars, but also those that are known to be innovative, or have an organizational culture supportive of faculty autonomy and innovation. ${ }^{10}$

Likewise, there is also a body of research describing employees who are at the very best relatively unproductive, if not deleterious to the outcomes of an organization and to their 
peers. These persons have been referred to as "deadweight" employees, i.e., those considered to be unproductive for lengthy periods of time, usually measured in academia by their lack of publications and funding, but additionally who might be especially problematic due to poor citizenship behaviors. ${ }^{11}$ The antecedents of faculty becoming deadweight have been evaluated, with much of the argument centering around the tenure system, with arguments that the processes and expectations required to obtain tenure, as well as the incentives provided by tenure, result in the development of star faculty, ${ }^{12}$ yet also create an environment conducive to some faculty becoming deadweights. ${ }^{13}$ The awarding of tenure in itself can be viewed as a recognition or reward for those who are or who may become stars, and there is research evincing that tenured faculty are more productive. ${ }^{14}$ However, there is also evidence to suggest that a proportion of tenured faculty go into years of "coasting". ${ }^{15}$ In any case, deadweight faculty's lack of productivity, particularly when coupled with poor attitudes, can become infectious, lowering the morale and productivity of other faculty. ${ }^{16}$

While researchers have examined factors that impact faculty recruitment and retention at schools and colleges of pharmacy, these studies have generally not examined the spectrum of faculty performance, and actions these schools may be taking to retain or attract "stars" and to improve or rid themselves of low performers/deadweight. Murawski and King examined the effects of salary on retention and productivity, noting the prevalence of inversion (where starting salaries accelerate more quickly for newer employees) and compression (where differences in salary among persons with considerable differences in experience become very small). Inversion and compression have been associated with faculty dissatisfaction and possible turnover among productive faculty. ${ }^{17}$ Pate discussed the importance of faculty engagement to boost productivity and morale and enhance organizational climate and culture for successful recruitment of faculty. ${ }^{18}$ The findings of various studies on academic pharmacy work life were reported by a task force convened by the American Association of Colleges of Pharmacy, which discussed the influences of organizational culture, mentorship, department chair support, and dean support. ${ }^{19}$ Kennedy described key roles played by deans and other administrators in establishing a culture of productivity in academic pharmacy. ${ }^{20}$ Deans of programs have considerable sway in promoting faculty development, in addition to the examples they set in handling deadweight faculty. ${ }^{21}$

Despite the importance of star faculty and the problematic nature of their deadweight counterparts, little has been researched in these areas within academic pharmacy. Given their importance in affecting the culture of the college/school of pharmacy, the perspectives of deans regarding the actions taken (retention, recruitment, development, dismissal, and other) for star and deadweight faculty are important to discern. The objectives of the study were to gather CEO deans' perspectives on: distinguishing star faculty versus those that are "merely productive"; faculty who are deadweight to the organization; the role of organizational fit in defining stars and deadweight faculty; current efforts to recruit and retain star faculty; and the actions taken in regard to deadweight faculty.

\section{METHODS}

\section{Study Design}

Study methods were deemed exempt from full review by the Touro University California Institutional Review Board (IRB). A qualitative study design was employed to gather rich viewpoints regarding these issues, particularly as terms such as "stars" and "deadweight" have not been defined in academic pharmacy literature and may not be commonly used by faculty and administrators. A focus group methodology was employed rather than individual interviews, as the research aimed to describe the phenomena of interest rather than induct theory, and it was believed that the participants would be able to listen to and respond to one another, jogging additional thoughts and ideas while concomitantly comparing and contrasting viewpoints from their experiences, especially given the diverse types of institutions that the participants would represent in terms of mission, ownership, infrastructure, resources, and geographic location. ${ }^{22}$ To that end, a phenomenological approach was taken; specifically, a philosophical perspective was sought from the participants that would emphasize their "lived experiences" and how those experiences have shaped their interpretations of events and general worldview. ${ }^{23}$

\section{Theoretical Framework}

The framework used in this study was adapted from an organizational theory framework employed by Roberts et al. ${ }^{24}$ This approach employs organizational change as its foundation and suggests that such change involve open communication and involvement among persons in all ranks and job types in the organization. Such an approach provides a useful perspective for recognizing the contributions of constituents within an organization, and in turn how their behaviors may affect each other and the organization as a whole. The organizational theory framework allowed the investigators to form the needed questions composing the interview guide, but also allowed for flexibility and agility in response to interview participants' initial answers (see Appendix 1). ${ }^{25.26}$ The interview guide explored "star" versus "merely good" performers; the roles of productivity in teaching, scholarship, and service; retention efforts made to even further develop and maintain star talent; the extent to which stars comport with various components of academic organizational culture; the salience of in-role and extra-role behaviors in the positive and negative outcomes for an academic organization; defining characteristics of deadweight faculty and/or those even more deleterious to the organization; actions to take in regard to these types of employees; and any possible perceived misalignment between administrators and faculty in describing stars and deadweight faculty, in addition to the actions taken in their regard. 


\section{Participants}

A sample of CEO deans from colleges/schools of pharmacy from around the U.S. were solicited to participate. While the process employed a focus group, participants were selected based upon tenets for selecting Delphi procedure participants. ${ }^{27}$ Specifically, participants were sought for their likelihood to contribute and be engaged in this process and whom others in the field would recognize as experienced and give credence. ${ }^{28}$ This was reconciled, as well, with seeking representation from schools varying in ownership (public versus private), foundational mission (teaching versus research versus balanced/comprehensive), and diverse geographic locations, as well as seeking representation along different characteristics of the participants, themselves (e.g., sex, race/ethnicity). As administrators evaluating and/or having oversight of faculty and program performance, they were deemed as having valuable input to share..$^{27,28}$

Potential participants were sought from attendees of the AACP 2019 Interim Meeting held in Tampa, Florida in late February 2019. Potential participants were contacted several weeks prior to the Interim Meeting via email to solicit their interest in participating. Of 18 CEO deans contacted, nine accepted the invitation to participate, and eight attended the session. All eight CEO deans who came to the session completed an informed consent agreement in which they agreed to be audio recorded, but not identified in any way. All eight participated in all aspects of the session, which lasted approximately 100 minutes. Characteristics of participants can be found in Table 1.

\section{Data Analysis}

With verbal consent of the participants, the interviews were conducted with notes taken during the process. The audio recording was used to create a written transcript of the discussion. The written transcript was then utilized to perform further content analysis. Directed content analysis was used to qualitatively analyze the interview transcript for patterns and themes. Directed content analysis is a flexible and foundational method in qualitative research and is commonly used in health care research. ${ }^{29}$ Since organizational theory was used as a guide for constructing initial questions, the directed content analysis results are based in part on theory constructs; however, the exploratory nature of this study behooved the researchers to allow germination of themes without an overly structured approach taken a priori. ${ }^{30}$ Still, a coding framework served as a basis for initial identification of thematic threads. The analysis was iterative and progressed through 3 cycles of recoding, relational linking, and synthesis of themes through the use of a network of nodes and branches for visualization and confirmation. Primary analysis and coding was undertaken by SD, with DZ serving in an advisory capacity during instances where SD was unsure or had issues not completely resolved. This process of visualizing the data through a prism of proximity matrices mimics the format used in NVivo qualitative analysis software output, although NVivo was not employed. ${ }^{31}$ This process, sometimes referred to as axial coding, involves creating empirical relationships by relating codes to each other using both inductive and deductive lines of reasoning.

\section{RESULTS}

Analysis of the data revealed 4 overarching themes: citizenship/organizational fit, faculty star qualities, star recognition, and deadweight versus toxic individuals. While all of the questions in the interview guide were touched upon, many participants kept referring back to citizenship of faculty, its importance, and the growing need to recognize good citizenship and call out bad behavior. Even though the interview guide was framed around an organizational behavior framework, the participants' responses revolved around organizational context and fit perhaps to an even greater extent than the investigators anticipated.

Following is a brief description of each theme, along with major points underscoring the theme, with supporting quotes from accompanying tables.

\section{Citizenship/Organizational Fit}

Even prior to asking specifically about citizenship/collegiality, some participants remarked specifically upon what it means for a faculty member to be a star. Organizational citizenship is a behavioral manifestation of collegiality, and is comprised of extra-role behaviors that are not expressly part of the job description but that which assists the institution and peers through good sportsmanship and other virtuous activity. Even prior to questions specifically about "deadweight" faculty, dean participants described the presence of positive citizenship and absence of negative citizenship behaviors. They also described good citizens as those faculty being team players, looking out for one another and, making a positive impact on the organization's climate, or overall mood. Supporting quotes for this theme can be found in Table 2 .

\section{Faculty Star Qualities}

The panel suggested that star faculty are ones who "deliver"; that is, they are able to leverage their talents. On the other hand, some talented faculty are unable to do so. They also reiterated that the stars are those who make it obvious that they are stars without necessarily trumpeting about it, while effectively networking with other colleagues.

In addition, the panel expressed that productive and very productive (star) faculty members are measured in the context of their discipline and other factors, and stressed that there are no absolutes in quantity for being referred to as a star. Table 3 provides supporting quotes, including comments related to annual performance reviews and on cycles/semesters of performance.

Throughout the discussion, even when not asked to describe or discuss "star" faculty specifically, participants referred back to behavioral manifestations of collegiality that transcend productivity, as well as characteristics, such as time 
management and thirst for knowledge, that usually lend themselves to those faculty becoming stars.

\section{Recognition of Stars}

Participants offered some concrete suggestions and ideas/programs being attempted at their institution to both maintain and recruit star faculty. The prevailing wisdom was that having a culture of recognizing top performers would make the institution attractive for those already there and for those elsewhere who might consider coming aboard. Participants concurred that both informal and more formal recognition go a long way for stars and for the entire faculty (see Table 4 for comments regarding the need to have star faculty recognized simply by having something to put on their CV and how these faculty are driven). One participant remarked on a program currently in place for staff that could (or some version of it) be extended to faculty.

Still, participants recognized the need for extrinsic rewards, as well, noting that when it is possible, i.e., that the budget allows for it, star faculty need to be compensated, as this sets a tone for them, which resonates throughout the program. Additionally, it should be communicated that financial rewards are tied to high-level performance, and deans should work with university officials to get creative. Regardless of type of awards, participants recognized the need to be proactive in retaining their star faculty (see Table 4 for comments about keeping the star faculty member from "getting on the airplane").

Still, the participants expressed some challenges in retaining of star faculty while attempting to maintain an ecumenical, collegial environment for all faculty.

\section{Deadweight versus Deleterious Individuals}

Panelists made strong distinctions between deadweight and deleterious individuals, with deadweight faculty being those demonstrating little productivity versus those who actually cause harm and damage to their colleagues and institutions. Panelists seemed to expect that within a larger group of individuals, there will almost invariably be some deadweight, and that the management options for them are limited. However, they felt strongly the need to snuff out individuals acting in a toxic way, which can be infectious and establish a pejorative organizational culture. Participants struggled to find good solutions to deadweight faculty, but yet did not seem to be bothered by their presence so much (see Table 5 for comments about evaluating if deadweight faculty are close to retirement and finding assignments that reinvigorate them).

In making the distinction between deadweight and deleterious faculty, the panelists articulated that dealing with the latter is even more problematic in the absence of guidance and support at the university/institutional level. While the panelists pointed out time and again that the toxic persons were far more problematic, they also indicated that dealing with them was in a sense easier, since their behaviors were clearer violations of conduct. The panelists agreed that being proactive is key (see Table 5 for comments on being in consistent dialogue with chairs and not putting off difficult conversations).

\section{DISCUSSION}

This study sought the collective opinions of CEO deans from U.S. pharmacy programs in a focus group. The participants highlighted the importance of having star faculty, pointing out that they are the ones relied upon to solve problems, innovate, and carry the organization forward. They also made distinctions between deadweight faculty versus those who are deleterious to the organization and to their colleagues. Kehoe et al. developed a typology of star employees, consisting of universal stars, performance stars, and status stars. ${ }^{32}$ The panelists from the current study touched upon all three, but primarily proffered their basis of "stardom" around the concept of universal stars. That is, they assumed that the stars would be productive in scholarship and in teaching, but that academic pharmacy stars transcend performance metrics, alone. In concordance with Kehoe et al's universal stars, the deans in this study honed in on stars' extraordinary dedication, putting the organization ahead of their own self-interest and helping those around them so that the entire organization is made a better place. These individuals likely promote a positive ethos and assist the organization in remaining calm in turbulent times, help create a reputation for the program that makes it attractive to both potential new students and potential new employees, reduces administrative burden, and allows supervisors and peers to focus on things that are more productive.

Perkmann et al. found that "faculty quality" was associated with enhanced engagement with related industries. ${ }^{33}$ This was found to be particularly the case with "star scientists", who are more likely to forge relationships that facilitate technological advancements, patents, co-funded grants, and mutually beneficial training opportunities for faculty and students, alike. This might especially be the case in the current environment of a shrinking student applicant pool and diminishing extramural funding opportunities, and with the remaining funding opportunities increasingly geared toward collaborative efforts and community partnerships that serve as regional economic engines. Academic pharmacy organizations and their star faculty look to collaborate with community partners in a variety of ways, including workforce development with the pharmaceutical industry. ${ }^{34,35}$ These collaborations, in addition to innovations, such as educational programs owning their own pharmacies, address community needs, diversify revenue streams, and serve as high-quality sites for experiential education. ${ }^{36.37}$

Even while panelists in this study described the benefits of having stars, they recognized the disconnect that might exist between whom they view as stars versus how "rank-and-file" faculty peers might view stars. Oldroyd and Morris describe how star employees create social capital and value for their 
organizations, yet might be sensitive to burnout and be the target of envy among peers who are less productive. ${ }^{38}$ Groysberg and Lee recommend that star faculty be recognized as exemplars for their organizations, but that public acts of praise be used judiciously while recognizing the contributions of other solid performers who might be not stars, per se. ${ }^{39}$

Those recommendations comport with the current study panelists' suggestions that high-performing faculty be given judicious amounts of recognition and, to the extent possible, rewarded tangibly with certain extrinsic rewards, which in tight budgetary times will require college administrators to be creative and seek solutions with university officials. Boyle highlighted the importance of recognizing excellence, offering advice for academic pharmacists to recognize one another effectively and harmoniously. ${ }^{40}$ Ziend et al., while not using the term "star", recognized the importance of engaging highly productive faculty in mentorship programs, with the understanding that these faculty be afforded opportunities to express their autonomy in creative ways and given credit in workload for mentoring. ${ }^{41}$

The participant dean panel consistently referred to stars in the context of citizenship behaviors, beginning with a sense of volunteerism, but going above and beyond volunteerism to a selfless and team-oriented attitude to elevating the performance of peers and to networking, forging alliances, and demonstrating high levels of emotional intelligence. This comports with a measure of organizational citizenship behaviors in academic pharmacy comprised of domains in conscientiousness, altruism, courtesy, sportsmanship, and civic virtue. ${ }^{42}$ Recognizing its importance, AACP recently convened a task force on citizenship aimed to shed further light on its hopeful proliferation throughout the academy. ${ }^{43}$ Among the recommendations of this task force was to incorporate citizenship into faculty evaluations. Several dean panelists in the current study indicated that their programs were beginning to do so.

The evaluation of citizenship, and even the characteristics said to embody stardom in academic pharmacy, were described within the context of organizational culture, another concept increasingly recognized for its importance to organizational and constituent member outcomes. ${ }^{19}$ Participants repeatedly prioritized the need for stars to assist with helping the organization achieve, innovate, and build relationships. ${ }^{44}$ Yet, the panel also acknowledged that high performance, particularly in research and scholarship, as well as teaching, are a "given" for faculty stars, and their emphasis on collegiality must be reconciled against current organizational rewards systems that appear skewed more toward research productivity than citizenship behaviors.

On the other end of the spectrum, the dean panel described low performers, but made very clear distinctions between deadweight faculty versus those who are more deleterious.
While it is preferable not to have or to minimize the number of deadweight employees in an organization, evidence suggests that these deadweight faculty can be overcome with a higher prevalence of top performers. ${ }^{45}$ However, there is evidence to suggest that the presence of just a few deleterious, or toxic members of a faculty can fuel job dissatisfaction, anger, stress, and even decrements in the productivity of peers. ${ }^{46}$ Clark et al., in a review of faculty incivility, described these actions in the context of these persons "playing games", and offered suggestions for peers and administrators on methods for thwarting these. ${ }^{47}$

Still, dealing with unproductive and deadweight faculty was said to be challenging, and this has been acknowledged outside of pharmacy. ${ }^{48}$ While not necessarily toxic/deleterious, an overabundance of deadweight faculty sets the tone for an unhealthy culture. ${ }^{49}$ There have been a number of suggestions proffered for dealing with such faculty; however, many of them revolve around post-tenure review, ${ }^{13}$ which is becoming less salient with the increasing number of faculty in non-tenuretrack positions. It has been suggested that while challenging, it is indeed possible to develop deadweight faculty, ${ }^{16}$ particularly with use of junior colleagues and post-graduate students who might serve to energize and rekindle flames among those who might otherwise be burned out.

\section{Study Limitations}

The results of the study should be taken in light of several limitations. The study employed the use of a focus group with a purposive sample of individuals attending a conference; and thus, the results are not generalizeable, even to other academic pharmacy deans. The views were generated entirely by CEO deans who are experienced and have been "in the trenches". Further research is required to discern the views of other administrators and faculty with no administrative experience to identify discrepancies in their opinions that might demand reconciliation or adjudication. In use of a focus group, the researchers cannot rule out the possibility that groupthink may have occurred, even among a set of participants representing programs and institutions quite varied in nature. Only one focus group was conducted. There was no attempt at saturation, and it is quite possible that a different group of participants could have produced alternative viewpoints.

The backgrounds of the investigators involved in this study present both a strength and a limitation. The two investigators are both at the rank of full professor, each with over 20 years of experience. Each investigator has served in nonadministrative faculty roles, as well as in administrative roles including department chair, assistant/associate dean, and CEO dean. Both were educated/trained with a PhD in social and administrative pharmaceutical sciences at doctoral-granting institutions and have worked at both public and private institutions. Their experience and their education/training provide them with the background to have undertaken this endeavor, as well as to communicate with/moderate the focus 
group participants, as they (researchers) were well versed in the issues and thus able to discern and even effectively probe for information, when needed from the participants. However, different researchers perhaps with less experience and/or with different education/training backgrounds could have moderated the focus group differently, thus yielding different data, and could have interpreted these or other data in a different manner. Finally, while the researchers brought extensive experience into the process, there was no attempt at triangulation, nor any attempt to evince confirmability or transferability as per Lincoln and Guba. ${ }^{50}$

\section{Future Research}

As with any focus group, the learning from the limited number of participants sheds light on the need to gather opinions from additional deans, as well as from department chairs and faculty themselves. Other research can help determine the veracity of the opinions from this small group of CEO deans by studying faculty who have been promoted, and given favorable assignments, as well as those who have been released from their positions or otherwise "demoted" and reconcile those perspectives against the deans' reports here. Another avenue of study would be to examine faculty handbooks and/or specific college policies and procedures of the most recent versus older versions and perform a content analysis to determine the extent to which these sorts of things (about culture and citizenship, for example) have been incorporated into more recent versions of such documents. Research could inquire whether those who engage in these behaviors feel as fulfilled as those who are producing more scholarship. Research could enumerate or quantify various behaviors that are considered detrimental or toxic, such as ascribing a 'value' to them through an interval-level or ratio scale. Research could potentially determine if indeed such acts of 'stardom' negate or even trump actions that are deadweight or toxic (perhaps they do trump deadweight but not toxic actions) for the organization as a whole.

\section{CONCLUSION}

A focus group discussion among CEO academic pharmacy deans regarding star and deadweight faculty uncovered four themes: identification of the behaviors that constitute a star; recognizing stars in the context of retaining existing and recruiting future members to the organization; the critical nature of citizenship behavior and organizational fit; and suggestions for dealing with deadweight versus more deleterious faculty. The research corroborated the growing recognition of the importance of faculty comportment with behaviors that extend beyond performance metrics, alone. The findings here can serve as a platform for additional studies that guide decision making for organizational effectiveness in academic pharmacy.
Funding/Support: None. The project was supported in part by intramural funds from the Touro University College of Pharmacy and its Masters of Science degree program.

Conflicts of Interest: None

\section{REFERENCES}

1. Call M. Organizational value capture, embeddedness, and status notification among star employees. Doctoral dissertation. University of South Carolina. Dissertation Abstracts International Section A: Humanities and Social Sciences; 77:(12-A(E); 2017.https://scholarcommons.sc.edu/etd/3502

2. Call ML, Nyberg AJ, Thatcher SMB. Stargazing: An integrative conceptual review, theoretical reconciliation, and extension for star employee research. J ApplPsychol. 2015;100(3):623-640. doi: 10.1037/a0039100.

3. Downs L. Star talent: investing in high-potential employees for organizational success. Industrial and Commercial Training. 2015;47(7):349-355. doi: 10.1108/ICT-06-2015-0041.

4. Kim J. Three essays on strategic human capital, managers and competitive advantage. Doctoral dissertation. Purdue University. Dissertation Abstracts International Section A: Humanities and Social Sciences. 79(10-A)(E); 2018.https://search.proquest.com/docview/2055249 431

5. Reigle DA. Hiring the right employees. J Med Pract Manage. 2014;30(3):183-186.

6. Riesz NJ. Keeping the human in human resources: finding and keeping star employees. Clin LeadershManag Rev. 2002;16(6):419-427.

7. Zucker LG, Darby MR. Star scientists and institutional transformation: Patterns of invention and innovation in the formation of the biotechnological industry. Proceedings of the National Academy of Sciences of the United States of America. 1996;93(23):1270912716. doi:10.1073/pnas.93.23.12709.

8. Zucker LG, Darby MR. Movement of star scientists and engineers and high-tech firm entry. National Bureau of Economic Research Working Paper. No. 12172. June 2014.doi: 10.3386/w12172.

9. White CS. What makes a "research star"? Factors influencing the research productivity of business faculty. Intl J Productivity Performance Manag. 2012;61(6):584-602.doi: 10.1108/17410401211249175.

10. Lowe RA, Gonzalez-Brambia C. Faculty entrepreneurs and research productivity. J Technol Transfer. 2007;32(3):173-104.doi: 10.1007/s10961-006-9014-y

11. Gerstenber $D$. As the twig is bent: faculty development. ADE Bull. 1981;n67:19-21.doi: 10.31274/rtd-180813-5189. 
12. Bess JL. Contract systems, bureaucracies, and faculty motivation: the probable effects of a no-tenure policy. J Higher Educ. 1998;69(1):1-22.doi: 10.1080/00221546.1998.11775123,

13. Nikolioudakis N, Tskliras AC, SomarakisS,Stergiou KI. Tenure and academic deadweight. Ethics SciEnviron Polit. 2015;15(1):87-93. doi: 10.3354/esep00166,

14. Chen Y, Gupta A, Hoshower L. Factors that motivate business faculty to conduct research: an expectancy theory analysis. J Educ Business. 2006;81(4):179189.doi: 10.3200/JOEB.81.4.179-189.

15. Faria JR, McAdam P. Academic productivity before and after tenure: the case of the 'specialist'. Oxford Economic Papers. 2015;67(2):291-309.doi: 10.1093/oep/gpv002.

16. Chen YF, Zoega G. Life-cycle, effort, and academic deadwood. University of Dundee. ; 2010. Available at: https://discovery.dundee.ac.uk/en/publications/lifecycle-effort-and-academic-deadwood. Accessed 20 January, 2020.

17. Murawski MM, King BJ. Influence of salary on faculty recruitment and retention: Current pharmacy faculty salaries relative to past faculty, community practitioners, and new hires. Currents Pharm Teach Learn. 2011;3(4):267-282.doi: 10.1016/j.cptl.2011.07.007.

18. Pate A, Smith J, Caldwell D, Horace A, Zagar M. Development, implementation, and impact of a collaborative junior faculty engagement and professional growth program: The Young Faculty Leadership Initiative. Curr Pharm Teach Learn. 2018;10:352-359. doi: 10.1016/j.cptl.2017.12.001.

19. Desselle SP, Peirce GL, Crabtree BL, Acosta D, et al. Pharmacy Faculty Workforce Issues: Findings from the 2009-2010 COD-COF Joint Task Force on Faculty Workforce. Am J Pharm Educ. 2011;75(4): Article 63.doi: 10.5688/ajpe75463.

20. Kennedy RH, Gubbins GO, Luer M, Reddy IK, Light KE. Developing and sustaining a culture of scholarship. Am J Pharm Educ. 2003;67(3): Article 92.doi: 10.5688/aj670392.

21. Andrews HA. The dean and the faculty. New directions for community colleges. In: Robillard, Ed. Dimensions of Managing Academic Affairs in the Community College.San Francisco, CA: Jossey Bass; 2000.

22. Cutcliffe JR. Methodological issues in grounded theory. J Adv Nurs. 2000;31(6):1476-1484.doi: 10.1046/j.1365-2648.2000.01430.x.

23. McPhail JC. Phenomenology as philosophy and method. Remedial Special Educ. 1995;16(3):159165.doi: 10.1177\%2F074193259501600305.
24. Roberts AS, Benrimoj SI, Chen TF, Williams KA, et al. Understanding practice change in community pharmacy: A qualitative study in Australia. Res Social Adm Pharm. 2005;1(4):546-564. doi: 10.1016/j.sapharm.2005.09.003.

25. Boyle TA, Bishop AC, Mahaffey T, Mackinnon NJ, et al. Reflections on the role of pharmacy regulatory authority in enhancing quality related event reporting in community pharmacies. Res Social Adm Pharm. 2014;10(2):387-397. doi: 10.1016/j.sapharm.2013.06.002.

26. Weightman R, Dewett T. Handbook of Organizational Change and Innovation. London: Oxford University Press; 2004.

27. Dalkey N, Helmer H. An experimental application of the Delphi Method in the use of experts. Manag Science. 1963;9(3):458-467.doi: 10.1287/mnsc.9.3.458.

28. Delbecq AL, Van de Ven AH, Gustafson DH. Group Techniques for Program Planning: A Guide to Nominal Groups and Delphi Process. Glenview, IL: Scott Foresman Company; 1975.

29. Cavanaugh S. Content analysis: concepts, methods and applications. Nurse Res. 1997;4(1):5-13.doi: 10.7748/nr.4.3.5.s2.

30. Vaismoradi M, Turunen $\mathrm{H}$, Bondas T. Content analysis and thematic analysis: Implications for conducting a qualitative descriptive study. Nurs Health Sci.2013;15:398-405. doi::10.1111/nhs.12048.

31. Leech, NL, Onwuegbuzie, AJ. Beyond constant comparison qualitative data analysis: Using NVivo. School Psychol Quart. 2011;26(1):70-84.doi: 10.1037/a0022711.

32. Kehoe RR, Lepak DP, Bentley FS. Let's call a star a star: Task performance, external status, and exceptional contributors in organizations. J Manag. 2016;44(5):1848-1872.doi: 10.1177/0149206316628644.

33. Perkmann M, King Z, Pavelin S. Engaging excellence? Effects of faculty quality on university engagement with industry. Res Policy. 2011;40(4):539-552.doi: 10.1016/j.respol.2011.01.007.

34. Martin GS. Northeastern and Glaxosmithkline launch joint experiential PhD program. Available at: https://news.northeastern.edu/2018/01/23/northeas tern-university-and-glaxosmithkline-launch-jointexperiential-phd-program/. Accessed on 31 July, 2019.

35. Mellillo S, Gangadharan A, Johnson H, Schleck P, et al. Postdoctoral industry fellowships: A descriptive analysis of programs and postgraduate positions. Am J Health-Syst Pharm. 2012;69(1):63-68.doi: 10.2146/ajhp110104. 
36. Shadid J. Satisfaction of mail service and walk-in pharmacy patients in a university outpatient clinic setting. J Am Pharm Assoc. 2010;50(3):336.doi: 10.1331/JAPhA.2010.09129.

37. Brahm NC, Palmer T, Williams T, Clancy G. Bedlam community health clinic: a collaborative health care service for the medically indigent. J Am Pharm Assoc. 2007;47(3):398-403. doi: 10.1331/JAPhA.2007.06083.

38. Oldroyd JB, Morris SS. Catching falling stars: a human resource response to social capital's detrimental effect on information overload of star employees. AcadManag Rev. 2012;37(3):396-418.doi: 10.5465/amr.2010.0403.

39. Groysberg B, Eling-Lee L, Abrahams R. What it takes to make 'star' hires pay off. MIT Sloan Manag Rev. 2010;51(2):57-61.

40. Boyle CJ. Successful strategies to spotlight achievement and reward excellence. Am J Pharm Educ. 2018;82(10): Article 7041.doi: 10.5688/ajpe7041.

41. Zeind CS, Zdanowicz M, MacDonald K, Parkhurst C, et al. Developing a sustainable mentoring program. Am J Pharm Educ. 2005;69(5): Article 100. doi: 10.5688/aj6905100.

42. Desselle SP, Semsick GR. Identification and development of items comprising organizational citizenship behaviors among pharmacy faculty. Am J Pharm Educ. 2016;80(10): Article 168. doi: 10.5688/ajpe8010168.
43. Hammer DP, Bynum LA, Carter J, Hagemeier NE, et al. Revisiting faculty citizenship. Am J Pharm Educ. 2019. doi: 10.5688/ajpe7378.

44. Desselle S, Rosenthal M, Holmes ER, et al. Components of a measure to describe organizational culture in academic pharmacy. Am J Pharm Educ. 2017;81(10): Article 6022.doi: 10.5688/ajpe6022.

45. Pusey A, Sealey-Huggins L. Transforming the university: Beyond students and cuts. ACME. 2013;12(3):443-458.

46. DalPezzo NK, Jett KT. Nursing faculty: A vulnerable population. J Nurs Educ. 2010;49(3):132-136. doi: 10.3928/01484834-20090915-04.

47. Clark CM, Olend L, Kenski D, CardoniC.Exploring and addressing faculty-to-faculty incivility: A national perspective and literature review. J Nurs Educ. 2013;52(4):211-218.doi:10.3928/0148483420130319-01.

48. Weight M, Johnsrud LK. Post-tenure review: what matters to faculty. Rev Higher Educ. 2005;28(3):393420. doi: 10.1353/rhe.2005.0029.

49. Allen L. Nursing shortage continues as faculty shortage grows. Nurs Econ. 2008;26(1):35-40.

50. Lincoln YS, Guba EG. Naturalistic Inquiry. Newbury Park, CA: Sage Publications; 1985. 
Table 1. Characteristics of CEO Dean Participants/Their Institutions the Focus Group

Characteristic

\section{Institution Type (Ownership)}

Private

Public

Institution Carnegie Classification

Doctoral-Very High Research Activity

Doctoral-High Research Activity

Doctoral/Professional (No specific mention of degree of research activity)

Special focus-Medical (no specific mention of degree of research activity)

\section{Geographic Distribution (of Participant Institution)}

Mid-Atlantic

Midwest

South

West

Participant Sex

Female

Male

Participant Race/Ethnicity

Caucasian/White

Other race/ethnicity (non-White)

\section{Participants (No.)}

5

3

1

4

2

1

3

2

1

2

4

4

6

2 
Table 2. Participant Comments Supporting the Citizenship/Organizational Fit Theme

"I think the value component gets to citizenship as well. . You have somebody who is very productive but in terms of... and it's already sort of been mentioned, but someone who is willing to flex and work with others when it's necessary, and you know, understand that we have institutional priorities, and sometimes we have to shift and I need you to move away from that for a little bit, probably to something that's more important at the moment." (Participant 4)

". . . when I think of someone who is productive and valuable, it's someone [who doesn't] play a numbers game, I can have someone who's checked all the boxes. Yes, I need to be on one committee, and have two papers and what? And by the rubric they had done everything that they need to and yet they're not a significant contributor to the greater good."(Participant 6)

"They're not good team players" (Participant 2)

". . . you know . . . they cause trouble . . . it's their empire . . . And so I separate out those two, the productivity and the values... if you get one without the other." (Participant 5)

"It's nice to have people that identify potential problems, hopefully before they happen and identify potential steps to avert or address the problems. And I think that's critical. Versus people that watch and say, 'oh, this is a train wreck.'"' (Participant 3)

". . . And to me that's the greater good, as a high tide lifts all boats, right? So that's a greater good type of activity. And sometimes there's other faculty that aren't of that orientation ..." (Participant 1) 
Table 3. Participant Quotes Supporting the Faculty Star Qualities Theme

"I think they need to be knowledgeable, experts in their area, but that knowledge... they need to be able to impart that in a way that shows caring and compassion, not only to the students but also to their colleagues." (Participant 1)

"I would say good organizational and time management skills. So it can be good at one thing but never get any, anything else done. So be able to multitask, balance, be organized and admit when you're overwhelmed." (Participant 2)

Yeah, because... during annual performance reviews, uh, you know, people tend to be ranked based on how they rate relative to other faculty, and so there's not absolute numbers that you're looking for. So it's a, it's a relative term. (Participant 4)

". . . there are times where somebody may be overloaded and you know, for a semester, then the next semester they're not quite as engaged. So I don't really consider that unproductive as long as it's an acute phase and not, I think, not a chronic phase. (Participant 3)

". . . but sometimes you do see situations where persons have oodles and oodles of talent, but they don't have the ability to, to express it and to demonstrate it." (Participant 1)

"These are not stars because we've made them stars. They're shining, and that- they're shining for everyone. But casual observer would probably recognize that they were a star." (Participant 4)

". . they talk about their own accomplishments and what the reality of the situation is versus how we view what they're contributing to the organization. Um, so sometimes there's a bit of a disconnect." (Participant 2) 
Table 4. Participant Quotes Supporting the Recognition of Stars Theme

"The recognition and such, but awards I think are meaningful and, you know, to faculty, let's face it, it's really important if it's something they can add to their CV." (Participant 2)

"... faculty are driven. They ... have external connections, and their recognition or awards often come externally, through their associations, ... their research ... So what I tried to do is recognize when they received those awards. . they actually enjoy the external recognition as long as I also recognize them." (Participant 4)

"So we actually instituted something called Leaders at our college ... stands for leadership, excellence, accountability - which could be a big deal - And I give them a little trophy. And individuals, they tend to be staff people who have taken sufficient courage to speak up about something that needed to be done that typically would not be in their purview ... " (Participant 7)

"I think the financial part of awards is all-important. They, as part of that, they need to hear that they're stars. We need to hear directly, you know, you're... what you, what you contribute and leadership potential and just from their chair or a dean. And I've seen times when that didn't happen." (Participant 5).

.". if you can prevent the star faculty member from getting on the airplane, then, uh, it's a heck of a lot easier than it is on the backside because you know, they're going to come back with an offer." (Participant 8)

"One of the things that I do to try to retain folks, or at least attempt to retain them is um, to find out what keeps them here and what gives them satisfied. Bingo. If you know that and if it's something you can do for them and keep that joy piece strong, then you're more likely to retain them."(Participant 7)

"And, um, whether you put out an open call to faculty that want to be considered for it [AACP Leaders Fellowship Program] or do you go tap on the shoulder of people and, um, the people that come and without any asking and want to be, you know, are probably not the people that we would go tap on the shoulder of sometimes." (Participant 2)

"But sometimes I think that the rank and file faculty view different colleagues, the stars, than maybe what the department chair and the Dean might too." (Participant 2) 
Table 5. Participant Quotes Supporting the Deadweight Versus Deleterious Individuals Theme

"Deadweight is the person that does the absolute minimum, checks off all the boxes... shows up at 9:30 and is out the door by 3:30. They deliver their courses, they get the grades in on time, but they do ... absolutely nothing extra. And you know, they show up to the committee meetings unprepared... Deleterious is when they're really undermining people. They're toxic. . they could be putting the institution at risk by their behaviors ... and they oftentimes are the ones that mislead junior faculty and students." (Participant 2)

"... And then there are some that are just snarky and like it. I mean, they find joy in getting a rise out of other people and their department chair." (Participant 1)

"If they're deadweight, I want to look how close are they to retirement? If they have an appointment that is an administrative appointment that I have control over, I might take that appointment away from them. Um, you know, put them back in a regular faculty position. Uh, they're getting the message that it's not okay..." (Participant 4)

"And sometimes it is that they're just in the wrong seat, you know, and sometimes I doubt, , , This is a hard diagnosis to determine whether it's lack of confidence or willingness to, to do anything more than that. I think trying to get a handle on that then helps determine whether some type of change in assignments will reinvigorate them or... " (Participant 3)

"You may have a person who's very productive in terms of research ... they show up to class and then at least get average teaching evaluations. . But they're a jerk. We [our university] did not have a standard of faculty conduct and [then we] did. And after that time point, then that enabled us to include that as part of the annual evaluations."(Participant 2)

"... the egregious ones are a lot easier. .. it's just obvious that they had to go. But the others, the deadweight, the nonproductive individuals are very challenging because it affects the morale. And that's the piece that's so dangerous because it affects their colleagues." (Participant 1)

"The toxic folks, too. Even if it's not egregious. If they're just going in a faculty member's offices, closing the door and just having at it. Well, and you know, chronic whining, starting rumors, making unfounded accusations and such, and then trying to reel all that back in." (Participant 2)

"... in my opinion, that actively disruptive, going out to intentionally stir up messes and create problems. Then there's the passive one, the one who never responds to email and then you find out that a student in their class has a disability and has been trying to line up extended time on a test or something and just put the institution in major risk. That's where, you know, if there's communication with the chair, you know, the chair should be finding out those passive ones. .. [You] can't wait until annual evaluation."(Participant 8)

"You know, uh, I think about difficult conversations. And these are the things I try never to put off. If there's something that needs to be said to someone, let's get it over with, and let's do it now. Let's not wait until the annual evaluation." (Participant 4) 


\section{Appendix 1. Questions Comprising the Semi-Structured Focus Group Schedule}

1. Tell me what you would consider for a faculty member to be productive. Potential follow-up probes

a. Quality versus quantity. Are they mutually exclusive? Can somewhat not be productive (or unproductive) in both quantity and quality? Is quantity a simple 'counting' exercise or is there more to it than that? What about quality? Easily measured?

b. Similarly, to what extent is such productivity agreed upon by various stakeholders (within-institution peers, outside institution peers, administrators)?

c. To what extent is being productive gauged by or considered in context of the faculty's discipline, rank, and available resources? Or, is there a "gestalt" aspect to it, that you simply consider the entirety of it all?

2. Is being unproductive the direct opposite, or antithesis of what you (or we) just described, or do you contextualize being unproductive in a different sort of way that just being the mirror opposite of being productive?

3. When we say a faculty member is a good citizen in his/her organization, what does that mean to you?

\section{Potential follow-up probes}

a. Is being a good citizen defined solely by good (e.g., kind, virtuous, altruistic) acts? Can it be likewise defined by the absence of bad acts or behaviors?

b. Do you commission of good acts and bad acts as the opposites of one dimension in citizenship or two different dimensions?

c. To what extent do you see the same individual performing good and bad acts of citizenship concomitantly? Do some people perform relatively little of either and others perform quite a lot of both, or do you see persons who perform mostly good or mostly bad acts/behaviors of citizenship, and then relatively few of the other?

4. How and to what extent is good citizenship codified and/or recognized and/or rewarded at your institution?

\section{Potential follow-up probes}

a. Does a Faculty Handbook or similar define/describe collegiality or citizenship? If so, how or in what context? And again, if so, do you think the definition comports with what you and other faculty think it is?

b. Do you think citizenship should be recognized? Rewarded? If so, then how?

5. What would you consider to be the qualities of a faculty member that you would consider a "star"?

\section{Potential follow-up probes}

a. Does a star have to be very good in terms of productivity and citizenship (extrarole behaviors)? Or, is it possible that someone is so terrific in some aspect that they can be mediocre perhaps even below mediocre in other areas?

b. Even with the realm of productivity, can someone be a "star" if they are absolutely incredible in teaching or research, if they are relatively ordinary in the other? 
6. Do you consider someone a "star" within the context of the organization/institution fit, or would that same person be, or likely be a "star" in whichever kind of organization they are in?

Potential follow-up probes

a. How much are talent and hard work/dedication/perseverance factors in this? So how well or how easily can someone with talent and hard work transfer that to a different institution with a different (or even a similar) mission and still be a star?

b. What other factors might facilitate or impede a person's ability to be a "star" in another place besides their current institution?

7. To what extent does being a "star" comport with some of the basic foundations of academic organizational culture, specifically the following?
1. Achievement orientation
2. Social responsibility
3. Supportiveness
4. Innovation
5. Focus on people and equity
6. Stability

8. To what extent is being a "star" faculty of some sort recognized at your institution?

Potential follow-up probes
a. What are the various awards you have to recognized in-role and/or outer-role excellence in performance?
b. How much does and should input for such recognition come from various stakeholders, such as peers outside the institution, from students, and/or others?
c. Or their ways (formal and/or informal) that "star" faculty are recognized beyond awards? Or they recognized with higher pay? With administrative titles/responsibilities? Other?

9. Does your institution make a conscious effort to retain its "star" faculty? If so, then how?

\section{Potential follow-up probes}
a. Does college/school administration (eg, deans, dept chairs) make any special efforts through formal and/or informal means to keep their "star" faculty engaged and/or satisfied?
b. What does the broader university system do, if anything, to help retain its "star" faculty?

10. What SHOULD your organization do, if anything, to try to retain its "star" faculty?

11. What about its attempts, if any, to attract "star" faculty from other institutions?

\section{Potential follow-up probes}
a. Are job descriptions for open faculty positions written to attract "star" faculty. If so, then how?
b. To what extent is formal recruiting conducted to fill open positions? Is there in essence agreement among the persons involved as to what a "star" faculty member is when it comes to outside recruitment?
c. To what extent are their creative efforts to recruit "star" faculty even in the possible absence of a specific FTE, or line, for a person?
d. Are the efforts usually to lure someone into a higher rank or administrative position? Or, with similar rank but considerable benefits or terms (eg, endowment monies, budgetary control, auspices over a center, or similar such?


12. Do peer colleagues and/or staff contribute in any way? If so, then how? Is there genuine gratitude or envy of "star" faculty, or some degree of both?

13. What would you consider to be a faculty member who is "deadweight" or someone to be deleterious to the organization? Are those similar in concept or something unique?

Potential follow-up probe

a. What combination of in-role and extra-role performance/behaviors contribute to someone being "deadweight" or deleterious to the organization?

14. What, if anything, is done to address the problem of having faculty who are "dead weight" or deleterious to the organization?

Potential follow-up probe

a. What do college/school administrators do? Are their active attempts to terminate employment of these individuals, if possible (considering tenure and other factors)? Are these persons given unfavorable assignments? Not rewarded or recognized? Made uncomfortable, unsatisfied, and/or unengaged in any sort of way? Encouraged (directly or indirectly) to leave the institution?

15. What SHOULD be the role of the following in addressing faculty who are "deadweight" or deleterious to the organization?

1. College/school Dean?

2. College/school faculty Chair?

3. University administration?

4. Peers/colleagues? 